Running Head: PLMS in the general population

\title{
Prevalence and Determinants of Periodic Limb Movements in the General Population
}

\author{
José Haba-Rubio, $\mathrm{MD}^{1^{*}}$, Helena Marti-Soler, $\mathrm{PhD}^{2}$, Pedro Marques-Vidal ${ }^{3}, \mathrm{MD}, \mathrm{PhD}$, Nadia
}

Tobback, RPSGT ${ }^{1}$, Daniela Andries, RPSGT ${ }^{1}$, Martin Preisig, MD $^{4}$, Gérard Waeber, MD $^{3}$, Peter

Vollenweider ${ }^{3}, \mathrm{MD}$, Zoltán Kutalik, $\mathrm{PhD}^{2,5}$, Mehdi Tafti, $\mathrm{PhD}^{1,6}$ and Raphaël Heinzer, MD, MPH ${ }^{1,7}$

${ }^{1}$ Center for Investigation and Research in Sleep (CIRS), Lausanne University Hospital (CHUV), Lausanne, Switzerland; ${ }^{2}$ Institute of Social and Preventive Medicine (IUMSP), Lausanne University Hospital (CHUV), Lausanne, Switzerland; ${ }^{3}$ Department of Medicine, Internal Medicine, Lausanne University Hospital (CHUV) and Faculty of Biology and Medicine, Lausanne, Switzerland; ${ }^{4}$ Department of Psychiatry, Lausanne University Hospital (CHUV), Lausanne, Switzerland; ${ }^{5}$ Swiss Institute of Bioinformatics, Lausanne University, Switzerland; ${ }^{6}$ Center for Integrative Genomics, Lausanne University, Switzerland; ${ }^{7}$ Pulmonary Department, Lausanne University Hospital (CHUV), Lausanne,

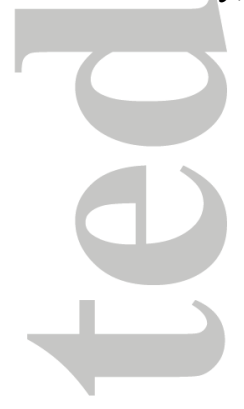

Switzerland.

*Corresponding author:

José HABA-RUBIO, MD

Centre for Investigation and Research in Sleep (CIRS)

Lausanne University Hospital (CHUV)

1011 Lausanne

Switzerland

Tel : +41(0)213146748

Fax : +41(0)213146752

Email : jose.haba-rubio@chuv.ch

This article has been accepted for publication and undergone full peer review but has not been through the copyediting, typesetting, pagination and proofreading process which may lead to differences between this version and the Version of Record. Please cite this article as an 'Accepted Article', doi: 10.1002/ana.24593 


Number of characters in the title: $80 \quad$ in the running head: 30
Number of words in the Abstract: 246
Number of words in the Introduction: 461
Number of words in the Discussion: 1492
Number of words in the body of the manuscript: 4414
Number of figures: 2
Number of color figures: 1
Number of tables: $6(3+3$ supplementary tables)
Number of references: 49

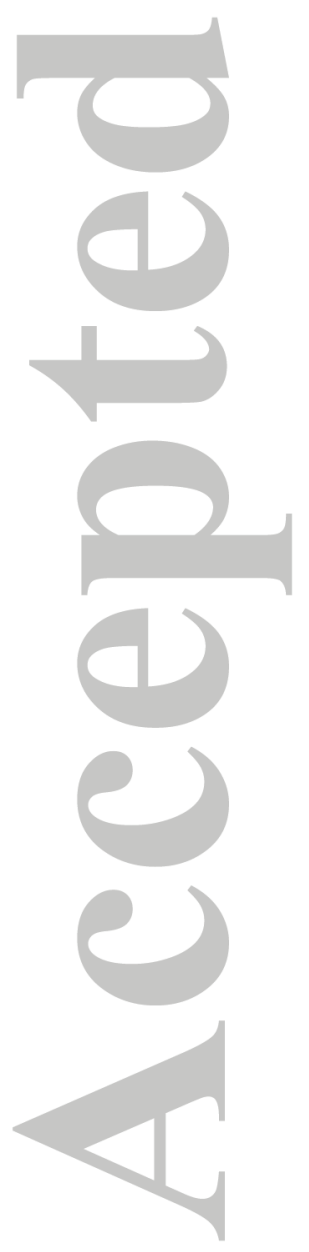




\section{Abstract}

Objective: Periodic limb movements during sleep (PLMS) are sleep phenomena characterized by periodic episodes of repetitive stereotyped limb movements. The aim of this study was to describe the prevalence and determinants of PLMS in a middle-to-older age general population.

Methods: Data from 2162 subjects (51.2\% women, mean age $58.4 \pm 11.1$ years) participating in a population-based study (HypnoLaus, Lausanne, Switzerland) were collected. Assessments included laboratory, socio-demographic, personal and treatment history, and full polysomnography at home. PLMS index (PLMSI) was determined and a PLMSI $>15 / \mathrm{h}$ was considered as significant.

Results: Prevalence of PLMSI $>15 / \mathrm{h}$ was $28.6 \%$ (31.3\% in men, $26 \%$ in women). Compared to subjects with a PLMSI $\leq 15 / \mathrm{h}$, subjects with a PLMSI $>15 / \mathrm{h}$ were older $(\mathrm{p}<0.001)$, predominantly males $(p=0.007)$, with a higher proportion of restless legs syndrome (RLS, $p<0.001$ ), a higher BMI $(p=0.001)$, and a lower mean glomerular filtration rate $(p<0.001)$. Subjects with a PLMSI $>15 / \mathrm{h}$ also had a higher prevalence of diabetes, hypertension, and betablocker or hypnotic treatments. The prevalence of antidepressant use was higher, but not statistically significant $(p=0.07)$. Single nucleotide polymorphisms (SNP) within BTBD9 (rs3923809), TOX3 (rs3104788) and MEIS1 (rs2300478) genes were significantly associated with PLSMI>15/h. Conversely, mean hemoglobin and ferritin levels were similar in both groups. In the multivariate analysis, age, male gender, antidepressant intake, RLS and rs3923809, rs3104788 and rs2300478 SNPs were independently associated with a PLMSI $>15 / \mathrm{h}$. 
Interpretation: PLMS are highly prevalent in our middle-age European population. Age, male gender, RLS, antidepressant treatment and specific BTBD9, TOX3 and MEIS1 SNPs distribution are independent predictors of a PLMSI $>15 / \mathrm{h}$.

Keywords: Periodic limb movements; polysomnography; restless legs syndrome

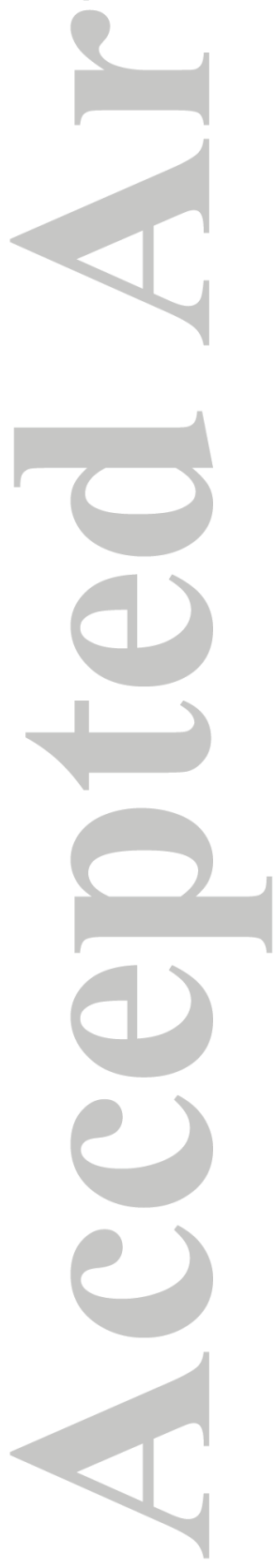




\section{Introduction}

Periodic limb movements of sleep (PLMS) are sleep-related phenomena characterized by periodic episodes of repetitive and highly stereotyped limb movements, which most often occur in the lower extremities. PLMS can be associated with brief arousals or full awakenings from sleep[1], and nearly all PLMS are accompanied by an autonomic reaction [2].

PLMS are frequently seen in restless legs syndrome (RLS), and excessive PLMS represents a supportive criterion for the diagnosis of RLS [3]. PLMS have been documented in other sleep disorders, such as sleep disordered breathing [4], narcolepsy[5] and REM sleep behavior disorder[6], as well as in several medical conditions, like renal failure [7], essential hypertension[8], Parkinson's disease[9], or associated with medication intake (in particular antidepressants and neuroleptics)[10]. Excessive PLMS have also been proposed as an independent cause of sleep disturbance. Periodic limb movement disorder (PLMD) is defined as the presence of $>15$ PLMS per hour and a complaint of insomnia and/or excessive daytime sleepiness with no other explanation for these symptoms[1]. In other cases, it is the bed partner who complains of being disturbed by these movements[1]. Furthermore, PLMS may be present without any complaint of disturbed sleep or daytime sleepiness, especially in elderly subjects.

Although the clinical relevance of PLMS is not completely established, evidence is emerging that, in addition to disturbing sleep, PLMS could be associated with an increased risk of cardiovascular disease by increasing sympathetic nervous system activity[11], even though a conclusive association and causality remains to be demonstrated[12]. 
PLMS are hypothesized to be related to dopaminergic dysfunction[13], explaining their frequent association with disorders involving dopaminergic transmission and the reduction of PLMS with dopaminergic agents[14].

Previous studies identified potential determinants of PLMS such as age, gender, coffee intake, use of hypnotics, although sometimes with conflicting results [15-17], probably due to the methods used to determine the presence of PLMS. A genetic predisposition has also been shown both in patients with RLS[18] and in the general population[17, 19], in particular with a common variant in an intron of the $B T B D 9$ gene on chromosome $6 \mathrm{p} 21.2$.

Studies of PLMS were carried out mostly in selected clinical populations (particularly in patients with RLS). Conversely, only a few used polysomnography (PSG) to determine the prevalence of PLMS in the general population $[16,17,19]$, some using questionnaires or telephone interviews[15]. Finally, not all earlier studies used the current scoring criteria and cut-offs to determine the presence of PLMS. Thus, the prevalence and determinants of PLMS in the general population are not well defined. Yet, it is important to determine their prevalence and their determinants, in order to assess their possible pathophysiology and their clinical significance.

The aim of the present study was thus to (1) estimate the prevalence of PLMS $>15 / \mathrm{h}$ in the general population, and (2) to identify associated risk factors.

\section{Methods}

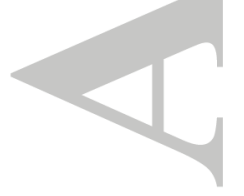




\section{Subjects}

The HypnoLaus Sleep Cohort study included subjects of the population-based CoLaus/PsyCoLaus Cohort study described previously [20-22]. Briefly, the CoLaus/PsychoLaus study included a random sample of 6733 subjects (range age: 35-75 years) selected from the residents of Lausanne city (Switzerland) between 2003 and 2006. The distribution of age groups, gender, and zip codes of participants were similar to the source population [20]. During the first follow up of the cohort, five years after the initial phase, all subjects who participated underwent a new physical $(n=5064)$ and psychiatric $(n=4000)$ examination. HypnoLaus evaluated the subjective and objective sleep characteristics in a random subset of this population. Sleep-related complaints and habits were investigated using several questionnaires among which the International Restless Legs Syndrome Study Group (IRLSSG) criteria for the diagnosis of RLS [23]. All subjects had a complete PSG at home. In the morning following the polysomnographic recording participants completed a questionnaire providing information about the quality of their sleep in the previous night, the amount of alcohol consumed 4 hours before going to bed, and their current medication.

CoLaus/PsyCoLaus and HypnoLaus were approved by the Ethics Committee of the University of Lausanne and a written informed consent was obtained from all participants.

\section{Polysomnography}

During a visit at the Center for Investigation and Research in Sleep (Lausanne University Hospital, Switzerland), trained technicians equipped the subjects with the PSG recorder (Titanium, Embla ${ }^{\circledR}$ Flaga, Reykjavik, Iceland) between 5 and 8 PM. All sleep recordings took 
place in the subjects' home environment and included a total of 18 channels, in accordance with 2007 American Academy of Sleep Medicine (AASM) recommended setup specifications[24]: six electroencephalography, two electrooculography, three surface electromyography (one submental, two for right and left anterior tibialis muscles), one for electrocardiogram, nasal pressure, thoracic and abdominal belts, body position, oxygen saturation and pulse rate. Surface leg electrodes were placed longitudinally and symmetrically around the middle of the muscle so that they were 2 to $3 \mathrm{~cm}$ apart or $1 / 3$ of the length of the anterior tibialis muscle, whichever was shorter. Separate channels for both legs were used.

All PSG recordings were visually scored by two trained sleep technicians (DA and NT) using Somnologica software (Version 5.1.1, by Embla ${ }^{\circledR}$ Flaga, Reykjavik, Iceland) and reviewed by a trained sleep physician (JHR). Random quality checks were performed by a second physician (RH). Quality control for concordance rate between the two PSG scorers was implemented periodically to ensure that both scorers achieved at least a 90\% level of agreement for sleep stages, PLMS and respiratory events and an $85 \%$ level of agreement for arousals[25].

Sleep stages were scored in 30 -sec epochs according to the 2007 AASM criteria[24]. Apneas, hypopneas and respiratory effort-related arousals were scored according to the 2012 AASM criteria[26]. The average number of apneas/hypopneas per hour of sleep (apnea-hypopnea index [AHI]) was calculated.

Periodic leg movements were scored according to the official World Association of Sleep Medicine (WASM) standards [27] by the following strict criteria: (1) duration between 0.5 to 10 sec; (2) minimum amplitude $>8 \mu \mathrm{V}$ in EMG voltage above resting EMG; (3) end of the event when the EMG decreased to $<2 \mu \mathrm{V}$ above the resting level and remained below that value for 0.5 
$\mathrm{s}$; (4) interval between 5 and $90 \mathrm{sec}$ between leg movement onsets; (5) movements had to be part of a series of $\geq 4$ consecutive movements meeting these criteria and (6) legs movements on 2 different legs separated by less than $5 \mathrm{sec}$ between movement onsets were counted as a single leg movement. Leg movements were not scored as PLMS if occurring at the end $( \pm 0.5 \mathrm{~s})$ of a respiratory event, defined as the beginning of the first breath that approximated the baseline breathing amplitude. The periodic leg movement in sleep index (PLMSI) was calculated by dividing the total number of PLMS by total sleep time in hours. Consistent with the ICSD-3 criteria, a PLMSI $>15 / \mathrm{h}$ was used as the cutoff criterion for elevated PLMSI [1].

Arousals were scored using standard criteria if there was an abrupt shift of EEG frequency including alpha, theta and/or frequencies greater than $16 \mathrm{~Hz}$ (but not spindles) that lasts at least 3 sec, with at least $10 \mathrm{sec}$ of stable sleep preceding the change. Scoring of arousal during REM required a concurrent increase in submental EMG lasting at least 1 sec [24]. Periodic leg movements were also quantified based on whether they were associated with an arousal. An arousal and a PLMS were considered associated if there were $<0.5 \mathrm{sec}$ between the end of one event and the onset of the other event, regardless of which was first [27].

\section{Clinical and Laboratory Measurements}

Blood pressure (BP) was measured in triplicate on the left arm and values averaged between the last two readings. Arterial hypertension was defined as a systolic BP (SBP) $\geq 140 \mathrm{mmHg}$ and/or a diastolic BP $(\mathrm{DBP}) \geq 90 \mathrm{mmHg}$ or current use of antihypertensive medication. The body-mass index (BMI) was calculated and subjects were classified as overweight if their BMI was between 25 and $30 \mathrm{~kg} / \mathrm{m}^{2}$ and obese if $\mathrm{BMI} \geq 30 \mathrm{~kg} / \mathrm{m}^{2}$. Smoking habit was self-reported and was 
dichotomized as current smoker/ex-smoker or never-smoker. Alcohol drinking was dichotomized as currently drinking or no alcohol consumption. Caffeine intake was estimated based on the number of cups recorded per day. Medication use at the time of sleep studies was recorded and coded according to the World Health Organization ATC classification

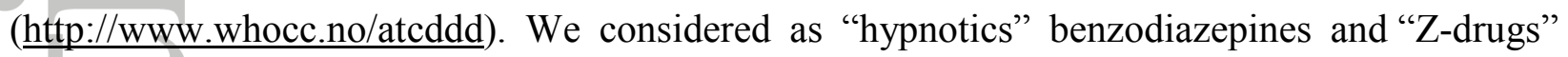
taken at night with a hypnotic purpose, and "benzodiazepines" taken during the day (for treating anxiety).

Blood samples were taken in the fasting state for biological measurements. Diabetes was defined as a fasting blood glucose level $\geq 7 \mathrm{mmol} / \mathrm{L}(126 \mathrm{mg} / \mathrm{dL})$ or current use of antidiabetic medication. Kidney function was measured by the estimated glomerular filtration rate (eGFR) calculated with the CKD-Epidemiology collaboration (CKD-EPI) equation[28], using creatinine from a morning fasting venous blood sample. Albuminuria was measured as albumin-tocreatinine ratio on a morning urinary spot. Participants were categorized as having either normal kidney function (eGFR $\geq 60 \mathrm{ml} / \mathrm{min} / 1.73 \mathrm{~m}^{2}$ without albuminuria), chronic kidney disease (CKD) Stage $1-2\left(\right.$ eGFR $\geq 60 \mathrm{ml} / \mathrm{min} / 1.73 \mathrm{~m}^{2}$ with albuminuria) or CKD Stage 3 (eGFR 30-60 $\mathrm{ml} / \mathrm{min} / 1.73 \mathrm{~m}^{2}$ ), according to the Kidney Disease-Improving Global Outcomes (KDIGO) classification[29]. Iron status was evaluated by the hemoglobin levels and red blood cell distribution width (RDW, an estimation in percent of the average distribution of red blood cell diameter, the value of RDW increasing in relation to iron deficiency[30]). We chose the RDW value $>14.5 \%$ as a tool to indirectly detect iron deficit[30]. Using a case-cohort approach ferritin was measured in a subsample $(n=619)$ randomly selected by stratified sampling from the HypnoLaus population, according to gender and 10-years age interval group. Multiple imputation was used to make inference to the whole cohort [31]. 


\section{Genotyping}

We used CoLaus/PsyCoLaus genome-wide genotype data and imputation, that has been described elsewhere [32]. Briefly, genotypes were measured on Affymetrix 500k array and only autosomal SNPs present in HapMap release 21 (390,631 measured scaffold SNPs) were used for imputation. Imputation was performed in 5435 CoLaus/PsyCoLaus participants using the method of Marchini et al.[33], using IMPUTE version 0.2.0. In total, 1594 subjects had both imputed genotype data and PLMSI measurements. Based on this analysis and in previously identified genetic determinants of PLMS [17-19] we examined candidate regions/single nucleotide polymorphisms (SNPs) and extracted genotype data for BTBD9 (rs3923809 [18], $\mathrm{r}^{2}$-hat=0.96), TOX3/BC034767 (rs3104788, r²-hat=1), MEIS1 (rs12469063 [17], $\mathrm{r}^{2}$-hat=0.97; rs2300478[19] is in high LD (0.95)), MAP2K5/SKOR1 (rs1026732[19] $\left(\mathrm{r}^{2}\right.$-hat=1), rs6494696[17], in perfect LD), and PTPRD (rs1975197[17] $\left(\mathrm{r}^{2}-\mathrm{hat}=1\right)$, rs10977209 [discovered in this analysis] $\left(\mathrm{r}^{2}-\right.$ hat $=0.91)$ ).

Statistical Analyses

Statistical analyses were performed using Stata version 11 (StataCorp, College Station, TX, USA), R (R Core Team, 2014)[34] and Matlab (The MathWorks Inc. version 8.3.0.532 (R2014a)). For descriptive statistics, continuous variables were summarized as mean \pm standard deviation (SD) or median \pm interquartile range (IQR), while categorical variables were summarized as number of subjects and percentages. We compared subjects with PLMSI $\leq 15 / \mathrm{h}$ and subjects with PLMSI $>15 / \mathrm{h}$ using the $\chi 2$ test, Student's $t$ test, or Wilcoxon's rank-sum test. 
We used Cohen's $d$ to calculate the effect size of the differences between participants who underwent polysomnography and those who did not. We performed multiple imputation for the analysis of the case-cohort data[31] using the mice package[35] in order to impute ferritin levels. Then we used logistic regression models to assess the association between demographic, clinical and genetic variables and a PLMSI $>15 / \mathrm{h}$.

Logistic regression was applied for 2,557,249 SNPs genome-wide, correcting for age and gender. Effect size, standard error and P-value were calculated for each SNP. We also applied linear regression for inverse normal quantile transformed raw PLMSI values using the same covariates.

The assessment of PLMS in the presence of sleep disordered breathing (SDB) is challenging by the fact that leg movements may be triggered by the respiratory events and are not part of a PLMS sequence. For this reason we also analyzed PLMS determinants in subjects without significant SDB, with an AHI cut-off value of 15/h[1].

Statistical significance was considered for a two-sided test $p$-value $<0.05$.

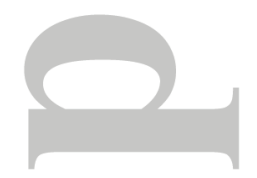

\section{Results}

\section{Description of the Sample}

Of 3043 consecutive subjects from the first follow-up of the population-based CoLaus/PsyCoLaus cohort study, 2168 (71.1\%) agreed to have a PSG at home. Technical problems resulting in insufficient data for PSG scoring were encountered in 60 cases $(2.8 \%) ; 54$ 
subjects accepted to repeat the PSG and 6 subjects declined, resulting in 2162 participants (51.2\% women, mean age $58.4 \pm 11.1$ years) included in the final analysis (Figure 1). Compared with the whole CoLaus/PsyCoLaus cohort, subjects who underwent PSG were similar in terms of age, sex, BMI, and ethnic origin, and they were representative of Lausanne's general population[20].

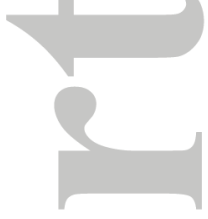

\section{General Characteristics}

For the whole population, the median (P05-P95) PLMSI was $2(0-64) / \mathrm{h}$, the upper 5\% centile was $73 / \mathrm{h}$ for men and $53 / \mathrm{h}$ for women, with a median duration of 2 (1-5) sec, and $18(0-76) \%$ were associated with an EEG arousal. PLMS were more frequent during stages 1 (median PLMSI: 15 (0-82)/h) and 2 (median PLMSI: 17 (0-90)/h), less frequent during stage 3 (median PLMSI: $9(0-121) / \mathrm{h})$ and rare during REM sleep (median PLMSI: $0(0-31) / \mathrm{h})$; ANOVA for PLMSI in stage 1, stage 2, stage 3, REM sleep, $\mathrm{p}<0.001)$.

\section{Prevalence of PLMSI $>15 / h$}

The overall prevalence of PLMSI $>15 / \mathrm{h}$ was $28.6 \%$ (31.3\% in men and $26.0 \%$ in women) in our middle to older aged general population sample. In the group with PLMSI $>15 / \mathrm{h}$, PLMS were present during all stages of NREM sleep, persisting during stage 3, but more rarely during REM sleep $(\mathrm{p}<0.001)$, and $14 \%$ of them were associated with an EEG-arousal. 


\section{Determinants of PLMSI $>15 / h$}

Compared to subjects with PLMSI $\leq 15 / \mathrm{h}$, subjects with a PLMSI $>15 / \mathrm{h}$ were significantly older, more frequently men, had a higher BMI and a higher prevalence of overweight and obesity. Subjects with PLMSI $>15 / \mathrm{h}$ also had an increased prevalence of hypertension, diabetes and a higher rate of postmenopausal women. For women, there were no significant differences between groups concerning the number of pregnancies (Table 1).

Regarding drug treatment, subjects with a PLMSI $>15 / \mathrm{h}$ reported more frequently taking hypnotics and betablockers, while borderline associations were found for antidepressants, antihistaminics and neuroleptics (Table 1). On the other hand, no differences were found for consumption of caffeine, alcohol or tobacco (Table 1).

Subjects with a PLMSI $>15 / \mathrm{h}$ reported more RLS-related symptoms (Table 1). However, three quarters of them did not complain about RLS. When stratifying PLMS+ subjects according to the presence or absence of RLS symptoms, RLS+ was associated with a higher proportion of women, psychotropic drug (neuroleptics, hypnotics, antidepressants and benzodiazepine) use and a lower AHI (Supplementary table 1).

Subjects with a PLMSI $>15 / \mathrm{h}$ had a higher AHI (Table 2). A weak correlation was found between the PLMSI and the AHI $(\rho=0.101, p<0.05)$, but this association disappeared when adjusting for age $(\mathrm{p}=0.575)$.

Concerning iron-related measurements, subjects with PLMSI $>15 / \mathrm{h}$ had a mildly increased RDW, while no significant differences were found between groups regarding hemoglobin or ferritin levels, or regarding the percentage of subjects with ferritin $<100 \mathrm{ng} / \mathrm{mL}$ (Table 2). 
Although the percentage of subjects with serum ferritin $<50 \mathrm{ng} / \mathrm{mL}$ tended to be higher in subjects with PLMSI $>15 / \mathrm{h}$, this difference was not statistically significant $(\mathrm{p}=0.155)$. No significant correlation was noted between the PLMSI and ferritin levels $(p=0.063)$. Otherwise, a PLMSI $>15 / \mathrm{h}$ was associated with lower glomerular filtration rate and higher percentage of CKD (Table 2).

GWAS analysis revealed BTB domain-containing 9 (BTBD9) gene as the region showing genome-wide significant association, and confirmed strong association of rs3923809 SNP with PLMSI[18]. The association between the A allele of rs3923809 and PLMSI $>15 / \mathrm{h}$ was genomewide significant at $\mathrm{p}=9.10 \mathrm{e}-10$. This association was further confirmed when subjects were grouped according to genotype into AA homozygotes (746 subjects, 46.8\%), AG heterozygotes (678 subjects, 42.5\%), and GG homozygotes (170 subjects, 10.7\%) (Supplementary table 2).

Note that these are (rounded) expected counts taking genotype uncertainty into account. For marker rs3923809, the PLMSI was greater in AA homozygotes than in AG heterozygotes $(16.42 \pm 0.87$ vs. $11.87 \pm 0.85 / \mathrm{h}, \mathrm{p}=1.84 \mathrm{e}-4)$ and greater in $\mathrm{AG}$ heterozygotes than in $\mathrm{GG}$ homozygotes $(11.87 \pm 0.85$ vs. $6.50 \pm 1.23, \mathrm{p}=3.39 \mathrm{e}-4)$. The PLMSI in AA homozygotes was almost threefold higher than in non A carriers (16.42 vs 6.50, $\mathrm{p}=5.33 \mathrm{e}-11)$. We also examined other candidate regions/SNPs. For dichotomized PLMS (PLMSI $>15 / \mathrm{h}$ versus $\mathrm{PLMSI} \leq 15 / \mathrm{h}$ ) we found significant associations for rs3104788 (TOX3) and for rs2300478 (MEIS1) (Supplementary table 2). When treating PLMSI as a continuous outcome variable, many more showed stronger replicating tendencies: TOX3 SNP rs3104788 ( $\mathrm{P}=1.98 \mathrm{e}-05)$, MEIS1 SNP rs2300478 (P=0.0452), MAP2K5 SNP rs1026732 (P=4.56e-03), PTPRD SNP rs1975197 $(\mathrm{P}=0.0141)$. Gene-based analysis also confirmed TOX3, MAP2K5 and PTPRD at 5\% FDR. 
Interestingly, we found another SNP (not in LD with rs197519) with stronger association in PTPRD (rs10977209 (P=7.27e-04)) surviving 5\% FDR.

\section{Multivariate analysis of the determinants of PLMSI $>15 / h$}

As a next step, we examined the association of a PLMSI $>15 / \mathrm{h}$ and predetermined variables from the univariate analysis and other previously reported possible determinants, using multiple imputation and a multiple variable logistic regression analysis, in order to determine independent predictors.

The factors significantly and independently associated with a PLMSI $>15 / \mathrm{h}$ were: age (OR (95\% $\mathrm{CI}): 1.07(1.05-1.08), \mathrm{p}<0.001)$, male gender (OR: $1.56(1.16-2.09), \mathrm{p}=0.003)$, antidepressant drugs intake (OR: 1.55 (1.02- 2.35), $\mathrm{p}=0.040)$, RLS (OR: $1.92(1.40-2.64), \mathrm{p}<0.001)$ and the alleles of rs3923809, rs3104788 and rs2300478 (Table 3). The strongest genetic association was found for the allele A of rs3923809 of the BTBD9 gene, with a risk ratio for homozygous (AA) compared to homorozygous $(\mathrm{GG})$ carriers estimated at $3.52(95 \% \mathrm{CI} 2.12-5.86, \mathrm{p}<0.001)$. The AHI showed a negative association (OR: 0.88 (0.77- 0.99), $\mathrm{p}<0.042)$. Conversely, no significant independent associations were found for BMI, hypertension, diabetes, alcohol, caffeine or tobacco consumption, or for the ferritin levels (Table 3).

Restricting the analysis to subjects without significant $\operatorname{SDB}(\mathrm{AHI}<15 / \mathrm{h})$ yielded similar results, with the additional findings that BMI became independently associated with the presence of PMLS $>15 / \mathrm{h}$, whereas allele distribution of the rs2300478 SNP was no longer significantly associated (Supplementary table 3). 


\section{Discussion}

To the best of our knowledge, the HypnoLaus Sleep Cohort study is the largest study assessing the prevalence and determinants of PLMS in a population-based sample. We found a high prevalence of PLMS in the general population: $28.6 \%$ of our sample had a PLMSI $>15 / \mathrm{h}(31.3 \%$ of men and $26.0 \%$ of women). When compared to subjects with a $P L M S I \leq 15 / h$, subjects with a PLMSI $>15 / \mathrm{h}$ were older, with a higher percentage of men and postmenopausal women and a higher BMI. A higher percentage of subjects had RLS, diabetes, hypertension and more of them were taking beta-blockers and antidepressants. Their mean glomerular filtration rate was lower, but the mean ferritin level was similar in both groups. We also found significant associations with allele distribution of SNPs within BTBD9 (rs3923809), TOX3 (rs3104788) and MEIS1 (rs2300478) genes. In the multivariate analysis, age, male gender, antidepressant intake, RLS and alleles of rs3923809, rs3104788 and rs2300478 were independently associated with a PLMSI higher than 15/h.

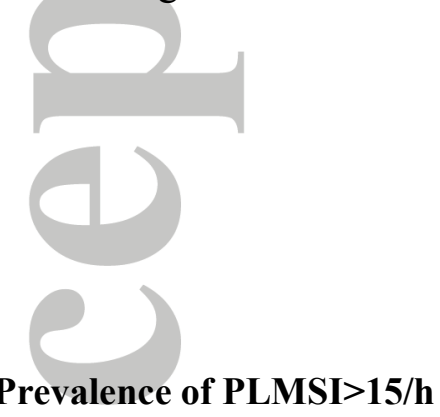

In our study, analyzing data from 2162 subjects representative of the adult general population of Lausanne, we found a prevalence of PLMSI $>15 / \mathrm{h}$ of $28.6 \%$. Scofield et al. reported a prevalence of $7.6 \%$ in a community-based sample of 592 participants drawn from the general population of Detroit Tri-County using standardized PSG criteria[16]. One possible explanation 
for this difference is the racial/ethnic distribution in the Scofield's study, with a large African American population, in which the prevalence of PLMS was found to be lower, whereas subjects participating in our study were almost exclusively of European origin. In addition, participants in their study were younger. Finally only an anterior tibialis EMG was used to record PLMS (instead of two separate channels for both legs as in our study), and leg movements were considered when their duration was between 0.5 to $5 \mathrm{sec}$ (instead of between 0.5 to $10 \mathrm{sec}$ as proposed in current scoring criteria[1, 24, 27]). These two technical factors could have contributed to an undervaluation of the presence of PLMS in Scofield's study. The estimate of the prevalence we found is closer to the $33 \%$ reported by Moore et al.[17]. In this study authors analyzed PSG data from 1090 participants on the Wisconsin Sleep Cohort, an epidemiological prospective study from the general population that included an enriched selection of people at risk for SDB. In this study a single-leg EMG channel was processed, and an automatic detector allowed recognition of PLM using a previously validated algorithm and slightly modified AASM scoring criteria. Recently, Winkelman et al. using 1993 AASM scoring criteria reported a much higher prevalence of PLMI $\geq 15(61 \%)$, in participants of the Osteoporotic Fractures in Men Study probably due to the fact that they analyzed data exclusively from community-dwelling men 65 years or older [19].

\section{Determinants of PLMSI $>15 / h$}

As previously described, we found in our study as association between increasing age and PLMS prevalence[16]. PLMS rarely occurs in children and adolescents without associated medical conditions[36], whereas in the elderly, PLMS are frequently observed, even in subjects without any sleep disturbance[37, 38]. 
In our study, male gender was associated with a higher prevalence of PLMS. Ohayon et al. reported a higher prevalence in women, but that study was based only on telephone interviews without PSG recordings to confirm the presence of PLMS[15]. Studies using objective methods to determine PLMS (either PSG[16, 17] or actigraphy[39]) also found a higher prevalence in males.

The occurrence of PLMS has been described in association with the intake of several medications, in particular with drugs impairing dopaminergic transmission and serotoninergic agents. The low frequency use of certain medications in our population, as neuroleptics, prevents from drawing definitive conclusions concerning a possible association with these specific drugs. Yet, we could show that the intake of antidepressants was independently associated with a PLMSI $>15 /$ h. Yang et al., analyzed data from 274 patients treated with antidepressants and found also a significant increase of PLMS during treatment, in particular in those treated with selective serotonin reuptake inhibitors and with venlafaxine[10]. Most other antidepressants can also induce or increase PLMS [40-42], with the exception of bupropion that seems to reduce them $[10,43]$.

Subjects with PLMS fulfilled more frequently the four cardinal diagnostic features of RLS[23].

This association between RLS and PLMS is well established and the presence of excessive PLMS supports the diagnosis of RLS [3]. This suggests RLS and PLMS may share, to some extent, the same pathophysiological origin. However, it must be stressed that RLS could be present without significant PLMS, and that as many as three quarters of subjects with a PLMSI $>15 / \mathrm{h}$ did not complaint of RLS. In subjects with PLSMS $>15 / \mathrm{h}$, RLS symptoms were more frequent in women and were associated with the intake of psychotropic drugs and with lower 
AHI. It is thus still unclear if RLS with and without PLMS correspond to different phenotypes[44].

In our study, we found a highly significant association between PLMSI and rs3923809, a common $\mathrm{A} / \mathrm{G}$ single-nucleotide variation in an intron of BTBD9 gene on chromosome 6 , pointing to a major genetic contribution to PLMS. The PLMS risk ratio for homozygous carriers (AA) to heterozygous carriers (AG) was estimated at 3.52, and the PLMI was correlated with the presence of allele A, homozygotes having almost threefold increase in leg movements per hour of sleep compared to non A carriers. Our data confirm the findings of Stefansson et al., who first described the association between rs3923809 and PLMS in subjects with RLS[18]. We also examined whether the genotype of this SNP modifies the association of clinically important risk factors (obesity, hypertension, diabetes, dyslipidemia), but no statistically significant interaction was observed. Two recent studies examined the association between PLM and single-nucleotide polymorphisms known to increase risk of RLS [17, 19]. We have also examined other candidate regions (including TOX3/BC034767, MEIS1, MAP2K5/SKOR1, and PTPRD). Three of them showed convincing $(<5 \%$ FDR) evidence of association with PLMSI: PTPRD (rs10977209, $\mathrm{p}=7.27 \mathrm{e}-4)$, MAP2K5 (rs2241420, $\mathrm{p}=5.69 \mathrm{e}-4)$ and TOX3 (rs3104788, p=1.98e-5). Allele distribution of the TOX3 (rs3104788) and MEIS1 (rs2300478) SNPs were significantly associated with PLSMI $>15 / \mathrm{h}$, even if these represent much weaker associations with PLM than rs3923809.

Stefansson et al. found an inverse correlation of the rs3923809 variant with iron stores, estimated by means of the ferritin index and the serum ferritin levels[18]. This finding is consistent with the suspected involvement of iron depletion in the pathogenesis of RLS, in which studies have clearly defined a role of brain iron deficiency in some patients with RLS, particularly in those 
with early-onset symptoms[45]. If a significant correlation has been shown between serum ferritin levels and RLS severity, no clear relationship between declining iron status and PLMS severity have been demonstrate[46].

\section{Strengths and Limitations}

The major strengths of our study is its population-based design, the large sample size, the availability of detailed information on a large number of demographic, clinical and genetic variables and the use of PSG to determine the presence of PLMS and sleep co-morbidities.

Nevertheless, we have to acknowledge potential limitations. First, our results are based on a single PSG, and an individual inter-night variability has been demonstrated in PLMS frequency[47]. The assessment of PLMS was performed using current scoring criteria of leg movements proposed by the WASM. The use of other scoring criteria, as those established by the AASM, could have led to different results in terms of frequency and prevalence of PLMS. Although these two major international scoring guidelines differ in their definition of respiratory related leg movements (LMs) both specifically exclude LMs occurring at the end $( \pm 0.5 \mathrm{~s})$ of respiratory events from the scoring of PLMS. It is however often difficult to differentiate movements supposed to be secondary to the arousal at the end of respiratory events to PLMS occurring independently and it has been shown that respiratory related LMs can occur in a time interval longer than the $0.5 \mathrm{sec}$ proposed by the current criteria[48]. It is therefore possible that some of the LMs that we have considered as PLMS were actually respiratory related. However, in the multivariate analysis, the AHI showed a negative association with the PLMSI, and when a 
subgroup with an AHI $<15 / \mathrm{h}$ was analyzed we found the same determinants of PLMSI $>15 / \mathrm{h}$ as in the whole population. We evaluated iron status with the ferritin levels (that reflects the storage iron compartment). We cannot exclude that other measures of iron, such as the serum transferrin receptor (that reflects the functional iron compartment) or a combination of indices could have given a clearer picture of functional iron status[49]. Finally, we included in our study subjects aged 40-85 years old only, almost exclusively of European origin. Thus, generalization of findings to younger people or to people from other ethnic backgrounds is limited.

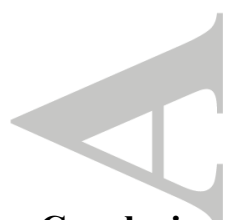

\section{Conclusions}

PLMS are highly prevalent in the general population. Age, male gender, antidepressant intake, RLS and alleles rs3923809 of the BTBD9, rs3104788 of the TOX3 and rs2300478 of the MEIS1 genes are independent predictors of a PLMSI $>15 / \mathrm{h}$. Further studies are needed to evaluate the clinical impact of PLMS.

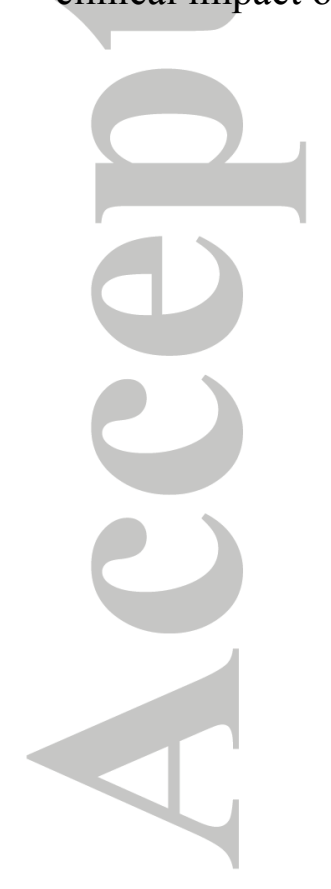




\section{Acknowledgements}

We would like to thank Vincent Mooser and all other investigators of CoLaus/PsyCoLaus study, who made the Hypnolaus study possible. The authors would like to express their gratitude to the Lausanne population who volunteered to participate in the HypnoLaus study. The HypnoLaus study was supported by grants from the Swiss National Science Foundation, from the Leenaards Foundation, from the Ligue Pulmonaire Vaudoise, from the CIRS and from GlaxoSmithKline. The CoLaus/PsyCoLaus study was supported by four grants of the Swiss National Science Foundation (\#105993, 118308, 139468 and 122661), the Faculty of Biology and Medicine (University of Lausanne) and two unrestricted grants from GlaxoSmithKline. ZK was supported by the Swiss National Science Foundation (31003A-143914), the Leenaards Foundation and SystemsX.ch (51RTP0 151019). The funders had no role in study design, data collection and analysis, decision to publish, or preparation of the manuscript.

\section{Author Contributions}

J.H.R., H.M.S., P.M.V., M.P., G.W., P.V., Z.K., M.T. and R.H. conceived and designed the study. J.H.R., H.M.S., N.T., D.A. Z.K., M.T. and R.H. acquired and analysed the data. J.H.R., H.M.S., Z.K., M.T. and R.H. drafted the manuscript and figures, and all authors were involved in subsequent revisions.

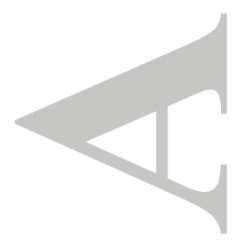




\section{Potential Conflicts of Interest}

The authors declare no potential conflicts of interest.
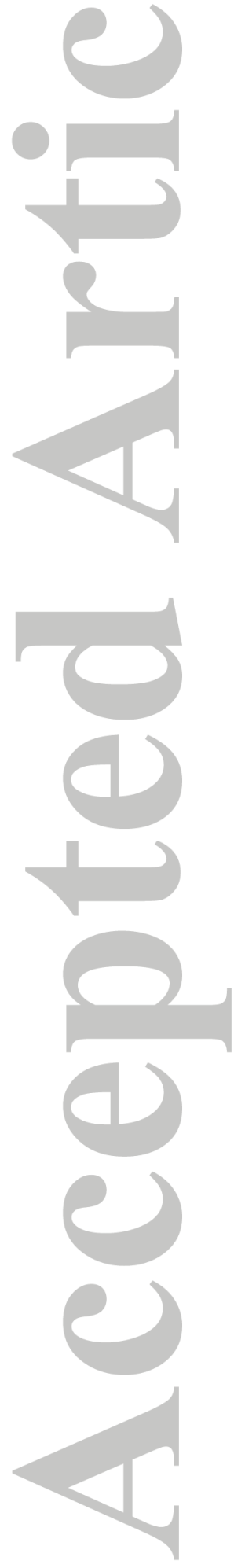

John Wiley \& Sons

This article is protected by copyright. All rights reserved. 


\section{References}

1. AASM. International classification of sleep disorders. Darien, IL: 2014.

2. Sforza E, Jouny C, Ibanez V. Time course of arousal response during periodic leg movements in patients with periodic leg movements and restless legs syndrome. Clin Neurophysiol 2003; 114: 11161124.

3. Allen RP, Picchietti DL, Garcia-Borreguero D et al. Restless legs syndrome/Willis-Ekbom disease diagnostic criteria: updated International Restless Legs Syndrome Study Group (IRLSSG) consensus criteria--history, rationale, description, and significance. Sleep Med 2014; 15: 860-873.

4. Chervin RD. Periodic leg movements and sleepiness in patients evaluated for sleep-disordered breathing. Am J Respir Crit Care Med 2001; 164: 1454-1458.

5. Baker TL, Guilleminault C, Nino-Murcia G, Dement WC. Comparative polysomnographic study of narcolepsy and idiopathic central nervous system hypersomnia. Sleep 1986; 9: 232-242.

6. Fantini ML, Michaud M, Gosselin N et al. Periodic leg movements in REM sleep behavior disorder and related autonomic and EEG activation. Neurology 2002; 59: 1889-1894.

7. Benz RL, Pressman MR, Hovick ET, Peterson DD. Potential novel predictors of mortality in endstage renal disease patients with sleep disorders. Am J Kidney Dis 2000; 35: 1052-1060.

8. Espinar-Sierra J, Vela-Bueno A, Luque-Otero M. Periodic leg movements in sleep in essential hypertension. Psychiatry Clin Neurosci 1997; 51: 103-107.

9. Arnulf I, Konofal E, Merino-Andreu M et al. Parkinson's disease and sleepiness: an integral part of PD. Neurology 2002; 58: 1019-1024.

10. Yang C, White DP, Winkelman JW. Antidepressants and periodic leg movements of sleep. Biol Psychiatry 2005; 58: 510-514.

11. Walters AS, Rye DB. Review of the relationship of restless legs syndrome and periodic limb movements in sleep to hypertension, heart disease, and stroke. Sleep 2009; 32: 589-597. 
cardiovascular system: is there a final answer? Sleep Med 2014; 15: 379-384.

13. Hornyak M, Feige B, Riemann D, Voderholzer U. Periodic leg movements in sleep and periodic limb movement disorder: prevalence, clinical significance and treatment. Sleep Med Rev 2006; 10: 169177.

14. Hening WA, Allen RP, Earley CJ et al. An update on the dopaminergic treatment of restless legs syndrome and periodic limb movement disorder. Sleep 2004; 27: 560-583.

15. Ohayon MM, Roth T. Prevalence of restless legs syndrome and periodic limb movement disorder in the general population. J Psychosom Res 2002; 53: 547-554.

16. Scofield H, Roth T, Drake C. Periodic limb movements during sleep: population prevalence, clinical correlates, and racial differences. Sleep 2008; 31: 1221-1227.

17. Moore Ht, Winkelmann J, Lin L et al. Periodic leg movements during sleep are associated with polymorphisms in BTBD9, TOX3/BC034767, MEIS1, MAP2K5/SKOR1, and PTPRD. Sleep 2014; 37: 15351542.

18. Stefansson $\mathrm{H}$, Rye DB, Hicks A et al. A genetic risk factor for periodic limb movements in sleep. $\mathrm{N}$ EnglJ Med 2007; 357: 639-647.

19. Winkelman JW, Blackwell T, Stone K et al. Genetic associations of periodic limb movements of sleep in the elderly for the MrOS sleep study. Sleep Med 2015; 16: 1360-1365.

20. Firmann M, Mayor V, Vidal PM et al. The CoLaus study: a population-based study to investigate the epidemiology and genetic determinants of cardiovascular risk factors and metabolic syndrome. BMC Cardiovasc Disord 2008; 8: 6.

21. Preisig M, Waeber G, Vollenweider P et al. The PsyCoLaus study: methodology and characteristics of the sample of a population-based survey on psychiatric disorders and their association with genetic and cardiovascular risk factors. BMC Psychiatry 2009; 9: 9.

\section{John Wiley \& Sons}



population: the HypnoLaus study. Lancet Respir Med 2015.

23. Allen RP, Picchietti D, Hening WA et al. Restless legs syndrome: diagnostic criteria, special considerations, and epidemiology. A report from the restless legs syndrome diagnosis and epidemiology workshop at the National Institutes of Health. Sleep Med 2003; 4: 101-119.

24. Iber C A-IS, Chesson A, and Qaun SF. The AASM Manual for the scoring of sleep and associated events : Rules, terminology and technical specifications. $1^{\text {st }}$ ed.: Westchester, Illinois: American Academy of Sleep Medicine 2007.

25. Redline S, Sanders MH, Lind BK et al. Methods for obtaining and analyzing unattended polysomnography data for a multicenter study. Sleep Heart Health Research Group. Sleep 1998; 21: 759767.

26. Berry RB, Budhiraja R, Gottlieb DJ et al. Rules for scoring respiratory events in sleep: update of the 2007 AASM Manual for the Scoring of Sleep and Associated Events. Deliberations of the Sleep Apnea Definitions Task Force of the American Academy of Sleep Medicine. J Clin Sleep Med 2012; 8: 597-619. 27. Zucconi M, Ferri R, Allen R et al. The official World Association of Sleep Medicine (WASM) standards for recording and scoring periodic leg movements in sleep (PLMS) and wakefulness (PLMW) developed in collaboration with a task force from the International Restless Legs Syndrome Study Group (IRLSSG). Sleep Med 2006; 7: 175-183.

28. Levey AS, Stevens LA, Schmid CH et al. A new equation to estimate glomerular filtration rate. Ann.Intern.Med. 2009; 150: 604-612.

29. KDIGO CKD Work Group. KDIGO 2012 Clinical Practice Guideline for the Evaluation and Management of Chronic Kidney Disease. Kidney Inter 2013; Suppl.: 1-150.

30. van Zeben D, Bieger R, van Wermeskerken RK et al. Evaluation of microcytosis using serum ferritin and red blood cell distribution width. Eur J Haematol 1990; 44: 106-109. 
Marti H, Chavance M. Multiple imputation analysis of case-cohort studies. Stat Med 2011; 30:

1595-1607.

32. Kutalik Z, Johnson T, Bochud M et al. Methods for testing association between uncertain genotypes and quantitative traits. Biostatistics 2011; 12: 1-17.

33. Marchini J, Howie B, Myers S et al. A new multipoint method for genome-wide association studies by imputation of genotypes. Nat Genet 2007; 39: 906-913.

34. Team RDC. R: A Language and Environment for Statistical Computing. Vienna, Austria : the R Foundation for Statistical Computing 2011.

35. Van Buuren SG-O, K. Multivariate Imputation by Chained Equations in R. Journal of Statistical Software $2011 ; 45:$ 1-67.

36. Kirk VG, Bohn S. Periodic limb movements in children: prevalence in a referred population. Sleep 2004; 27: 313-315.

37. Ancoli-Israel S, Kripke DF, Klauber MR et al. Periodic limb movements in sleep in communitydwelling elderly. Sleep 1991; 14: 496-500.

38. Carrier J, Frenette S, Montplaisir J et al. Effects of periodic leg movements during sleep in middle-aged subjects without sleep complaints. Mov Disord 2005; 20: 1127-1132.

39. Morrish E, King MA, Pilsworth SN et al. Periodic limb movement in a community population detected by a new actigraphy technique. Sleep Med 2002; 3: 489-495.

40. Fulda S, Kloiber S, Dose T et al. Mirtazapine provokes periodic leg movements during sleep in young healthy men. Sleep 2013; 36: 661-669.

41. Goerke M, Rodenbeck A, Cohrs S, Kunz D. The influence of the tricyclic antidepressant amitriptyline on periodic limb movements during sleep. Pharmacopsychiatry 2013; 46: 108-113. 
42. Hornyak M, Kopasz M, Rodenbeck A et al. Low-dose doxepin does not increase periodic leg movements in sleep in primary insomnia patients. Data from a randomized, double-blind, placebocontrolled trial. Somnologie 2005; 9: 111-115.

43. Nofzinger EA, Fasiczka A, Berman S, Thase ME. Bupropion SR reduces periodic limb movements associated with arousals from sleep in depressed patients with periodic limb movement disorder. J Clin Psychiatry 2000; 61: 858-862.

44. Baumann CR, Marti I, Bassetti CL. Restless legs symptoms without periodic limb movements in sleep and without response to dopaminergic agents: a restless legs-like syndrome? Eur J Neurol 2007; 14: $1369-1372$.

45. Dauvilliers Y, Winkelmann J. Restless legs syndrome: update on pathogenesis. Curr Opin Pulm Med 2013; 19: 594-600.

46. Sun ER, Chen CA, Ho G et al. Iron and the restless legs syndrome. Sleep 1998; 21: 371-377.

47. Sforza E, Haba-Rubio J. Night-to-night variability in periodic leg movements in patients with restless legs syndrome. Sleep Med 2005; 6: 259-267.

48. Manconi M, Zavalko I, Fanfulla F et al. An evidence-based recommendation for a new definition of respiratory-related leg movements. Sleep 2015; 38: 295-304.

49. Suominen P, Punnonen K, Rajamaki A, Irjala K. Serum transferrin receptor and transferrin receptor-ferritin index identify healthy subjects with subclinical iron deficits. Blood 1998; 92: 2934-2939. 
Figure legends

Figure 1: Studied population

PSG: Polysomnography

Figure 2: Prevalence of PLMSI throughout the entire range of potential cut-off values.

PLMSI: Periodic limb movements during sleep index.

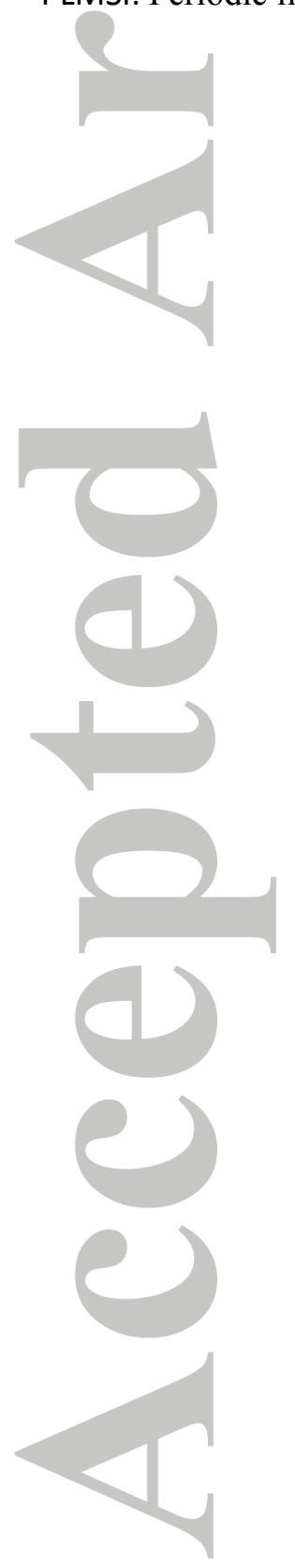

John Wiley \& Sons 
Table 1. Demographic and clinical characteristics of the study population, stratified by the presence of PLM.

\begin{tabular}{|c|c|c|c|c|}
\hline N (\%) & $\begin{array}{l}\text { TOTAL } \\
\mathrm{N}=2162\end{array}$ & $\begin{array}{c}\text { PLMSI } \leq 15 / \mathrm{h} \\
\mathrm{N}=1544(71.4 \%)\end{array}$ & $\begin{array}{c}\text { PLMSI }>15 / h \\
\mathrm{~N}=618(28.6 \%)\end{array}$ & $P$ value \\
\hline Age (years) ${ }^{*}$ & 59 (11) & 57 (11) & $64(11)$ & $<0.001$ \\
\hline Gender (women) & $1106(51.2)$ & $818(53.0)$ & $288(46.6)$ & 0.007 \\
\hline \multicolumn{5}{|l|}{ For women } \\
\hline Postmenopausal & $776(71.8)$ & $535(67.2)$ & 241 (84.9) & $<0.001$ \\
\hline Number of pregnancies $* *$ & $2(1-3)$ & $2(1-3)$ & $2(1-4)$ & 0.770 \\
\hline BMI $\left(\mathrm{kg} / \mathrm{m}^{2}\right)^{*}$ & $25.7(4.2)$ & $25.5(4.2)$ & $26.1(4.3)$ & 0.001 \\
\hline $\mathrm{BMI} \geq 25\left(\mathrm{~kg} / \mathrm{m}^{2}\right)$ & $1132(52.4)$ & $773(50.1)$ & $359(58.1)$ & 0.001 \\
\hline $\mathrm{BMI} \geq 30\left(\mathrm{~kg} / \mathrm{m}^{2}\right)$ & $291(13.5)$ & $190(12.3)$ & $101(16.3)$ & 0.016 \\
\hline Diabetes & 214 (9.9) & $126(8.2)$ & $88(14.2)$ & $<0.001$ \\
\hline Hypertension & $897(41.5)$ & $560(36.3)$ & $337(54.5)$ & $<0.001$ \\
\hline Restless legs syndrome & $321(18.0)$ & $191(15.0)$ & $130(25.3)$ & $<0.001$ \\
\hline \multicolumn{5}{|l|}{ Treatment } \\
\hline Neuroleptics & $41(1.9)$ & $24(1.6)$ & $17(2.8)$ & 0.069 \\
\hline Hypnotics & $187(8.8)$ & $121(8.0)$ & $66(10.8)$ & 0.037 \\
\hline Antidepressants & 209 (9.7) & $138(8.9)$ & $71(11.5)$ & 0.070 \\
\hline Betablockers & $184(8.5)$ & $108(7.0)$ & $76(12.3)$ & $<0.001$ \\
\hline Benzodiazepines & $117(5.4)$ & $85(5.5)$ & $32(5.2)$ & 0.761 \\
\hline Antihistaminics*** & $21(1.0)$ & $19(1.2)$ & $2(0.3)$ & 0.054 \\
\hline Alcohol consumption & $1825(85.2)$ & $1301(85.0)$ & $524(85.6)$ & 0.729 \\
\hline Coffee consumption & $2021(93.5)$ & 1435 (92.9) & $586(94.8)$ & 0.135 \\
\hline No & $141(6.6)$ & $106(7.2)$ & $32(5.2)$ & \\
\hline $1-3$ cups/day & $1412(66.4)$ & $987(65.1)$ & $425(69.6)$ & \\
\hline $4-6$ cups/day & $500(23.5)$ & $369(24.3)$ & $131(21.4)$ & \\
\hline$>6$ cups/day & $74(3.5)$ & $51(3.4)$ & $23(3.8)$ & \\
\hline Tobacco consumption & $398(18.6)$ & $290(19.0)$ & $108(17.7)$ & 0.484 \\
\hline
\end{tabular}




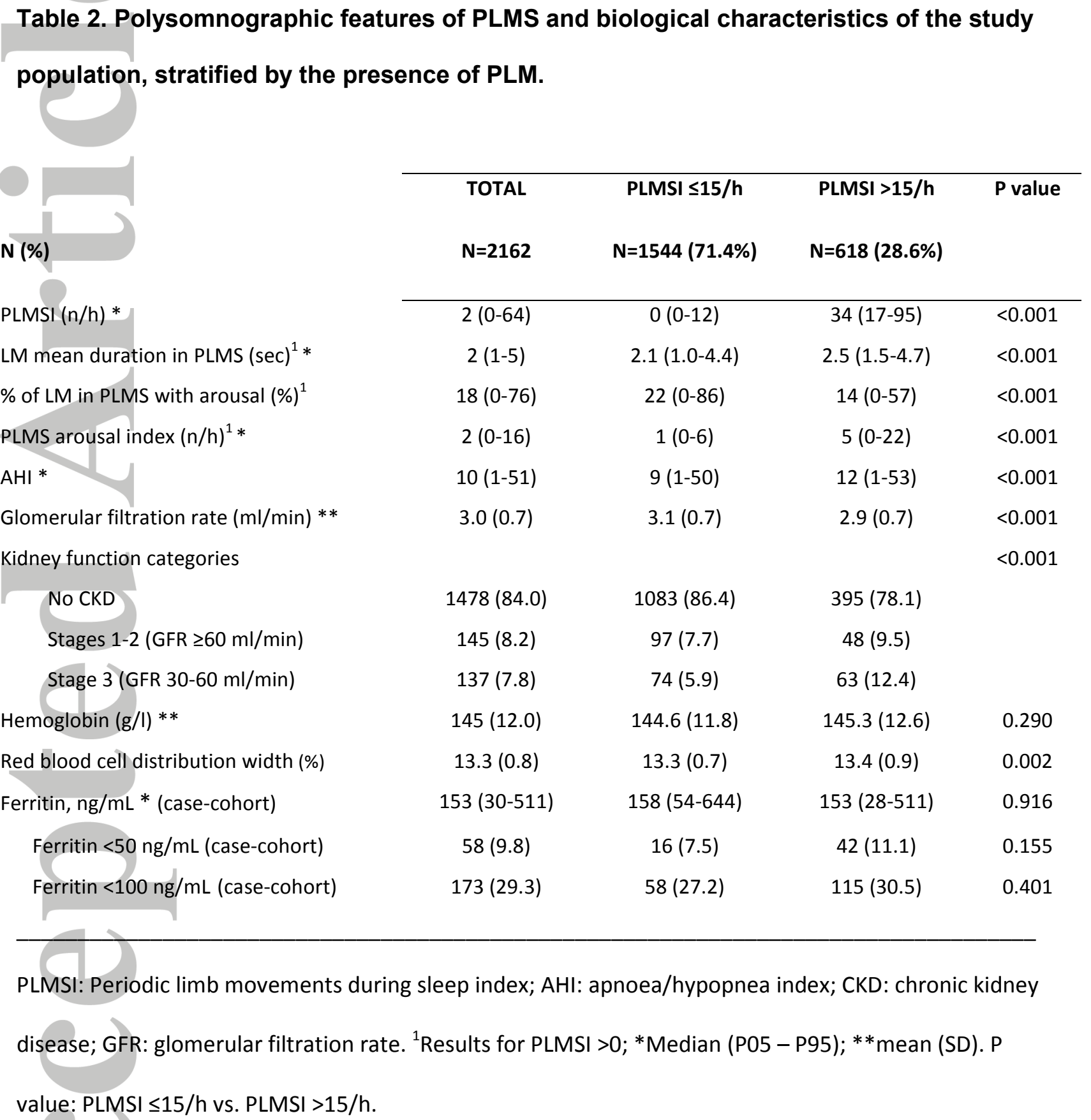


Table 3: Association between demographic, clinical and genetic features and PLMSI

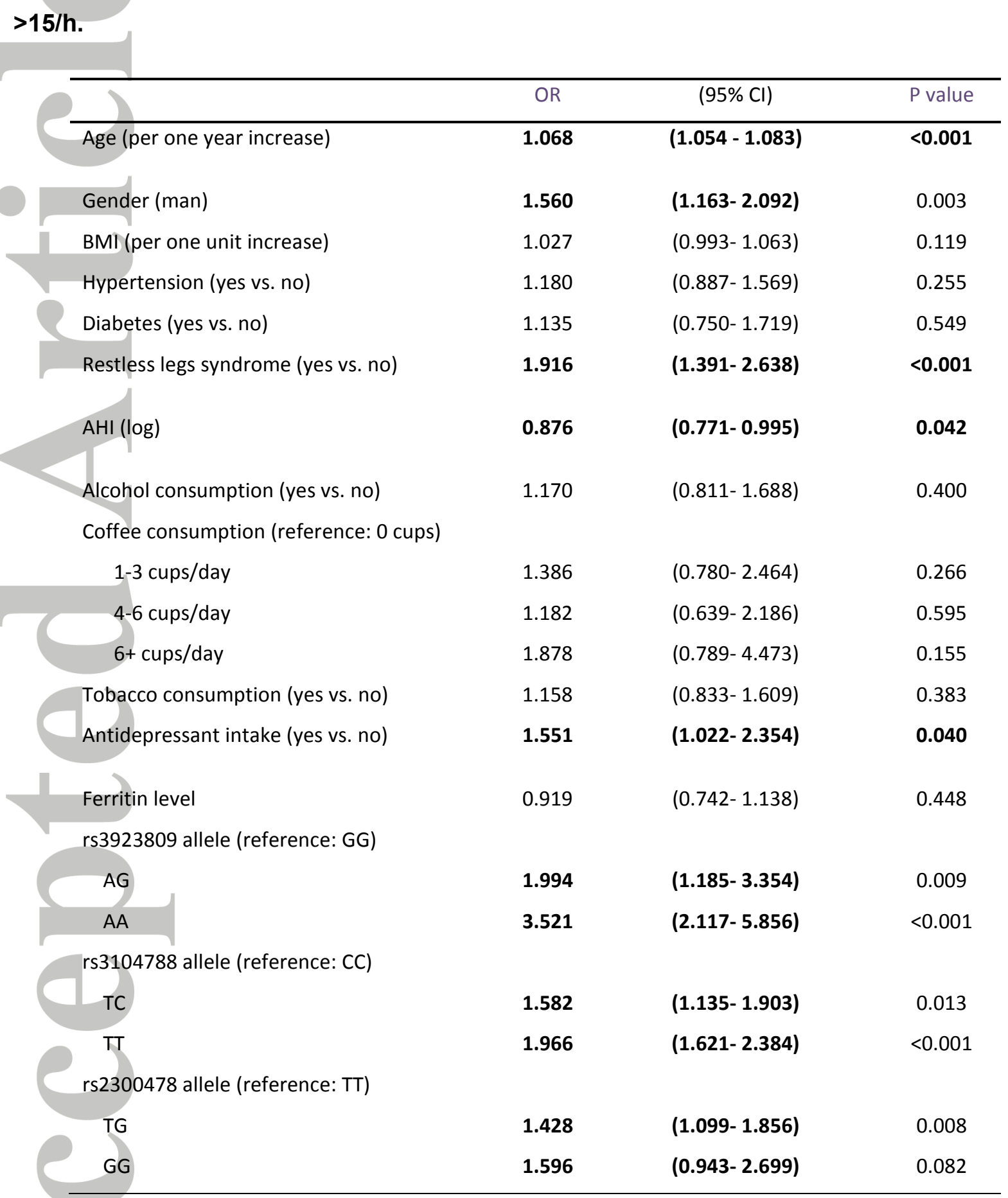

BMI: body mass index; AHI: apnoea/hypopnea index. Statistical analysis by logistic regression models. 


\section{Supplementary table 1. Characteristics of the population with PLMSI $>15 / h$, stratified by the presence of RLS.}

\begin{tabular}{|c|c|c|c|c|}
\hline $\mathbf{N}(\%)$ & $\begin{array}{c}\text { PLMSI }>15 / h \\
\qquad N=513\end{array}$ & $\begin{array}{c}\text { RLS - } \\
\mathrm{N}=383(74.7 \%)\end{array}$ & $\begin{array}{c}\text { RLS + } \\
\mathrm{N}=130(25.3 \%)\end{array}$ & $P$ value \\
\hline Age (years) ${ }^{*}$ & $64(11)$ & $64(10)$ & $63(11)$ & 0.209 \\
\hline Gender (women) & $249(48.5)$ & 172 (44.9) & $77(59.2)$ & 0.005 \\
\hline \multicolumn{5}{|l|}{ For women } \\
\hline \multicolumn{5}{|l|}{ Postmenopausal } \\
\hline \multicolumn{5}{|l|}{ Number of pregnancies $* *$} \\
\hline BMI $\left(\mathrm{kg} / \mathrm{m}^{2}\right)^{*}$ & $26.0(4.4)$ & $25.9(4.3)$ & $26.3(4.7)$ & 0.446 \\
\hline $\mathrm{BMI} \geq 25\left(\mathrm{~kg} / \mathrm{m}^{2}\right)$ & $290(56.5)$ & $217(56.7)$ & $73(56.1)$ & 0.920 \\
\hline $\mathrm{BMI} \geq 30\left(\mathrm{~kg} / \mathrm{m}^{2}\right)$ & $85(16.6)$ & $60(15.7)$ & $25(19.2)$ & 0.345 \\
\hline Diabetes & $70(13.7)$ & $49(12.8)$ & $21(16.2)$ & 0.335 \\
\hline Hypertension & $276(53.8)$ & $208(54.3)$ & $68(52.3)$ & 0.693 \\
\hline Restless legs syndrome & -- & -- & -- & -- \\
\hline \multicolumn{5}{|l|}{ Treatment } \\
\hline Neuroleptics & $10(2.0)$ & $4(1.1)$ & $6(4.6)$ & 0.021 \\
\hline Hypnotics & $23(4.5)$ & $16(4.2)$ & $7(5.4)$ & 0.037 \\
\hline Antidepressants & $43(8.5)$ & $26(6.9)$ & $17(13.2)$ & 0.028 \\
\hline Betablockers & $63(12.3)$ & $46(12.0)$ & $17(13.1)$ & 0.749 \\
\hline Benzodiazepines & $26(5.1)$ & $12(3.1)$ & $14(10.8)$ & 0.001 \\
\hline Antihistaminics*** & $2(0.4)$ & $0(0.0)$ & $2(1.5)$ & -- \\
\hline Alcohol consumption & $436(85.2)$ & $326(85.1)$ & $110(85.3)$ & 0.966 \\
\hline Coffee consumption & & & & 0.473 \\
\hline No & $24(4.7)$ & $16(4.2)$ & $8(6.2)$ & \\
\hline $1-3$ cups/day & $359(70.1)$ & $265(69.4)$ & $94(72.3)$ & \\
\hline $4-6$ cups/day & $108(21.1)$ & $83(21.7)$ & $25(19.2)$ & \\
\hline$>6$ cups/day & $21(4.1)$ & $18(4.7)$ & $3(2.3)$ & \\
\hline Tobacco consumption & $422(82.4)$ & $320(83.8)$ & $102(78.5)$ & 0.170 \\
\hline Mean PLMSI (n/h) & & $33(17-97)$ & $34(17-90)$ & 0.645 \\
\hline LM mean duration in PLMS $(\mathrm{sec})^{1} *$ & & $2(1-5)$ & $2(1-5)$ & 0.330 \\
\hline$\%$ of LM in PLMS with arousal (\%) & & $14(0-57)$ & $17(0-62)$ & 0.090 \\
\hline PLMS arousal index $(n / h)^{1} *$ & & $5(0-20)$ & $6(0-27)$ & 0.103 \\
\hline
\end{tabular}


AHI

$12(1-53)$

$10(1-36)$

0.021

Glomerular filtration rate $(\mathrm{ml} / \mathrm{min})$ **

Kidney function categories

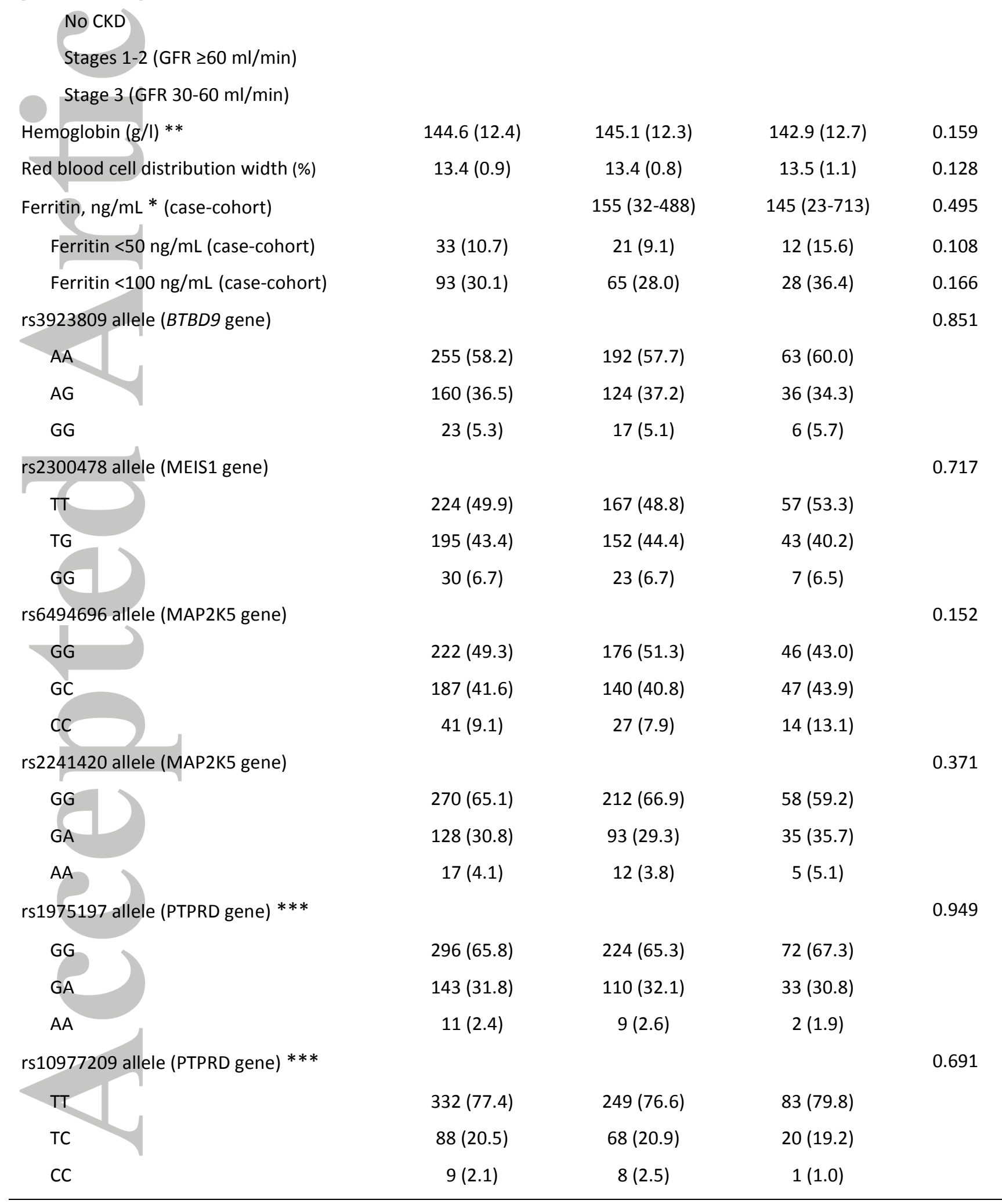

John Wiley \& Sons

This article is protected by copyright. All rights reserved. 
PLMSI: Periodic limb movements during sleep index; RLS: Restless legs syndrome; BMI: body mass index; AHI: apnoea/hypopnea index; CKD: chronic kidney disease; GFR: glomerular filtration rate. ${ }^{1}$ Results for PLMSI >0 *Mean (SD); **median (P05 - P95); *** Fisher's exact test. P value: PLMSI $\leq 15 / h$ vs. PLMSI $>15 / \mathrm{h}$
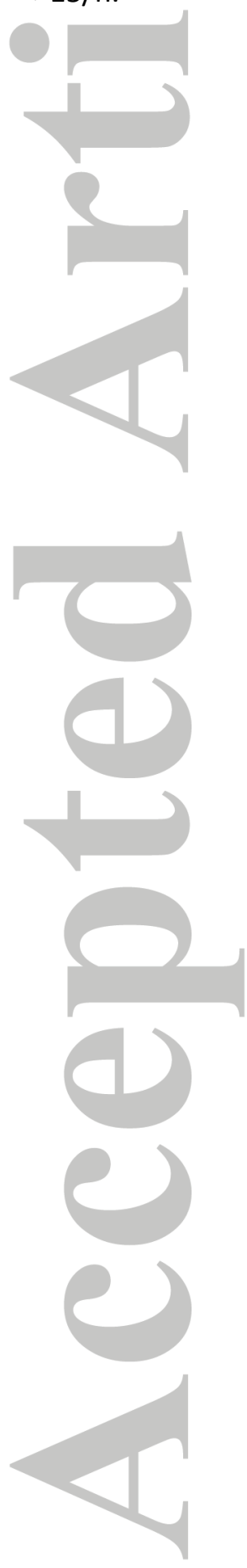

John Wiley \& Sons

This article is protected by copyright. All rights reserved. 
Supplementary table 2. Allele frequencies, stratified by the presence of PLMS.

\begin{tabular}{|c|c|c|c|c|}
\hline & TOTAL & PLMSI $\leq 15 / h$ & PLMSI >15/h & P value \\
\hline $\mathbf{N}(\%)$ & $N=2162$ & $\mathrm{~N}=1544(71.4 \%)$ & $\mathrm{N}=618(28.6 \%)$ & \\
\hline rs3923809 allele (BTBD9 gene) & & & & $<0.001$ \\
\hline AA & $746(46.8)$ & $485(42.8)$ & $261(56.7)$ & \\
\hline AG & $678(42.5)$ & $502(44.2)$ & $176(38.3)$ & \\
\hline GG & $170(10.7)$ & $147(13.0)$ & $23(5.0)$ & \\
\hline rs3104788 allele (TOX3 gene) & & & & 0.013 \\
\hline $\mathrm{TT}$ & $577(32.9)$ & $376(30.9)$ & $201(37.4)$ & \\
\hline $\mathrm{TC}$ & $857(48.8)$ & $603(50.0)$ & $254(47.2)$ & \\
\hline C & $321(18.3)$ & $238(19.6)$ & $83(15.4)$ & \\
\hline rs2300478 allele (MEIS1 gene) & & & & 0.011 \\
\hline $\mathrm{TT}$ & $983(56.2)$ & 710 (58.5) & $273(50.8)$ & \\
\hline TG & $665(38.0)$ & $437(36.0)$ & $228(42.5)$ & \\
\hline $\mathrm{GG}$ & $102(5.8)$ & $66(5.4)$ & $36(6.7)$ & \\
\hline rs6494696 allele (MAP2K5 gene) & & & & 0.298 \\
\hline GG & $803(45.7)$ & $542(44.5)$ & $261(48.5)$ & \\
\hline $\mathrm{GC}$ & $783(44.6)$ & $554(45.5)$ & $229(42.8)$ & \\
\hline CC & $169(9.6)$ & $121(9.9)$ & $48(8.9)$ & \\
\hline rs2241420 allele (MAP2K5 gene) & & & & 0.058 \\
\hline GG & $945(59.5)$ & $634(57.7)$ & $311(63.3)$ & \\
\hline GA & $560(35.2)$ & $399(36.3)$ & $161(32.8)$ & \\
\hline AA & $84(5.3)$ & $65(5.9)$ & $19(3.9)$ & \\
\hline rs1975197 allele (PTPRD gene) & & & & 0.620 \\
\hline GG & $1180(67.3)$ & $824(67.8)$ & $356(66.2)$ & \\
\hline G & $526(30.0)$ & $357(29.4)$ & $169(31.4)$ & \\
\hline AA & $48(2.7)$ & $35(2.9)$ & $13(2.4)$ & \\
\hline rs10977209 allele (PTPRD gene) & & & & 0.147 \\
\hline T & $1278(75.8)$ & $886(75.5)$ & $392(76.3)$ & \\
\hline TC & $386(22.9)$ & $275(23.4)$ & $111(21.6)$ & \\
\hline $\mathrm{CC}$ & $23(1.4)$ & $12(1.0)$ & $11(2.1)$ & \\
\hline
\end{tabular}

PLMSI: Periodic limb movements during sleep index. Single nucleotide polymorphisms (SNP) are grouped according to gene (chromosome in parenthesis. P value: PLMSI $\leq 15 / h$ vs. PLMSI >15/h. 
Supplementary table 3: Association between demographic, clinical and genetic features and PLMSI > 15/h in participants with apnoea-hypopnoea index $<15 / \mathrm{h}$.

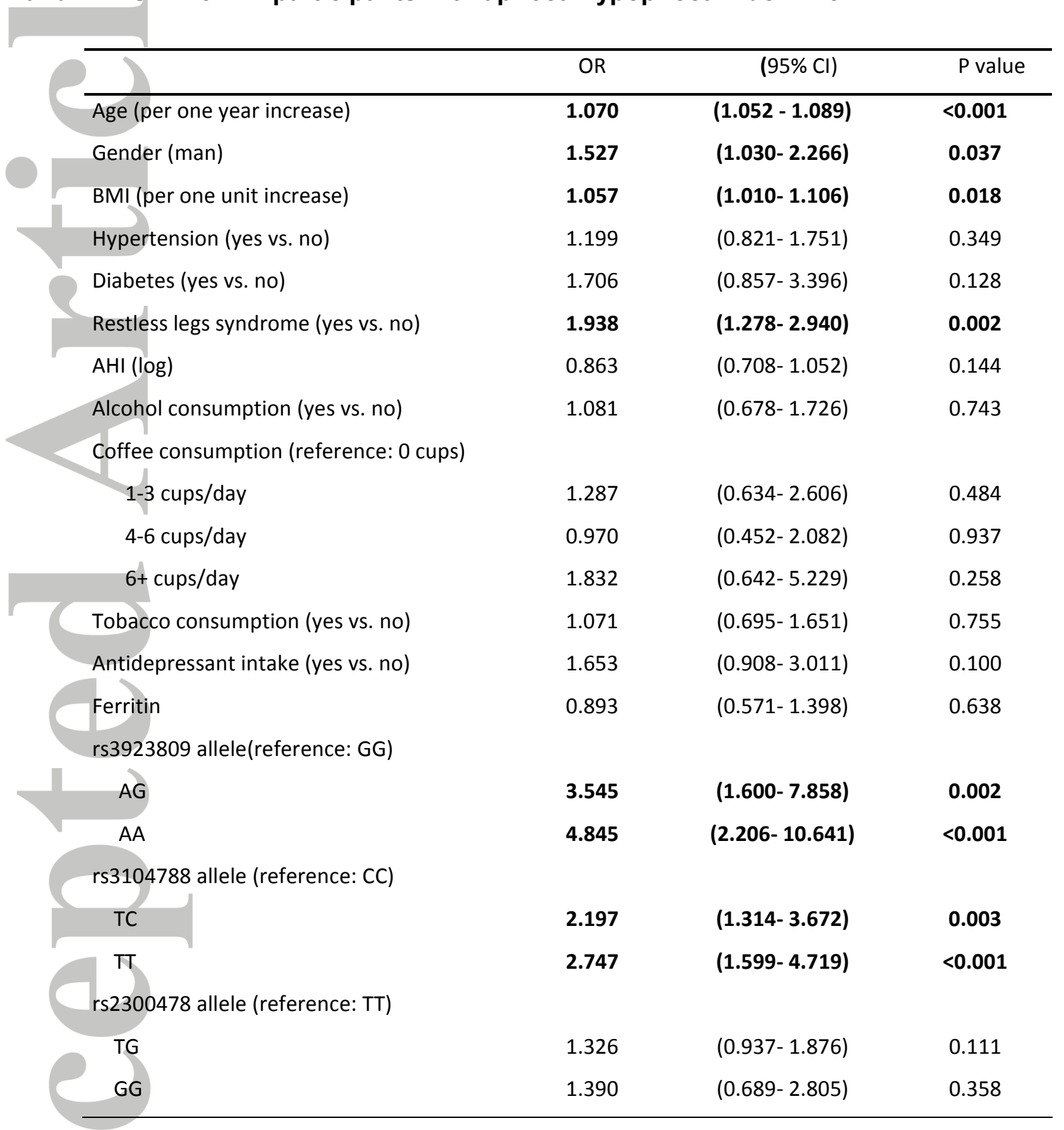

BMI: body mass index; AHI: apnoea/hypopnea index. Statistical analysis by logistic regression models.

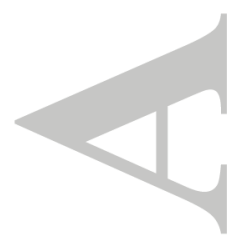




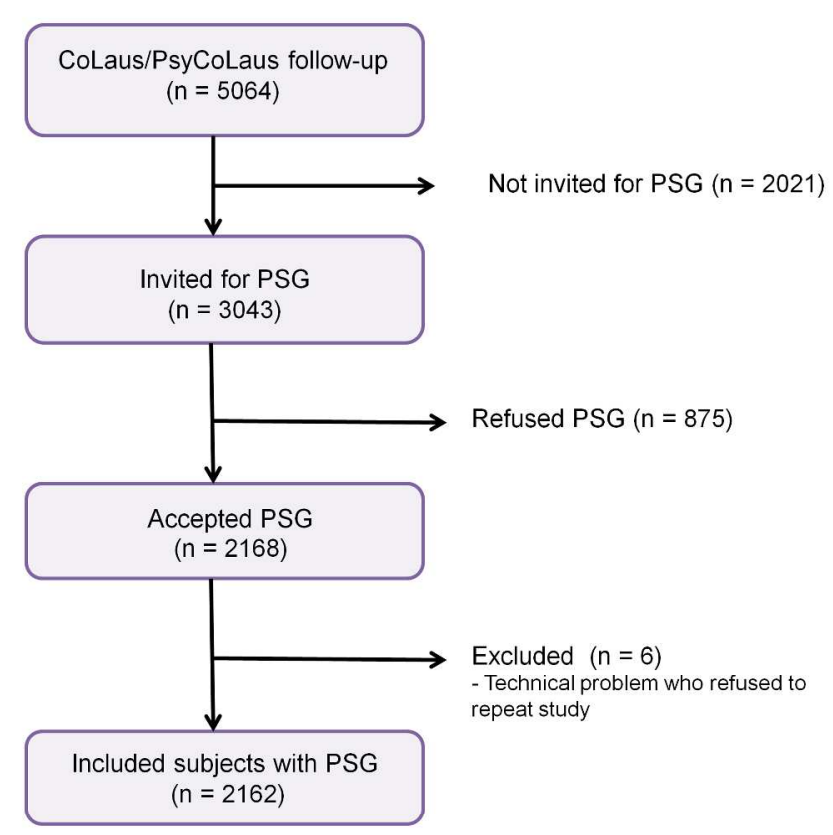

PSG: Polysomnography

Figure 1: Studied population $254 \times 190 \mathrm{~mm}$ (300 x 300 DPI)

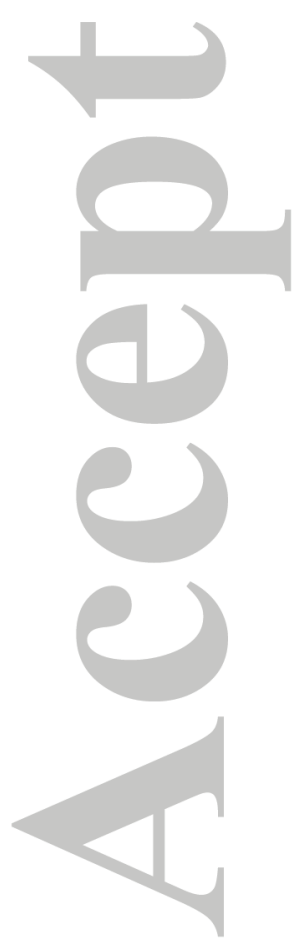




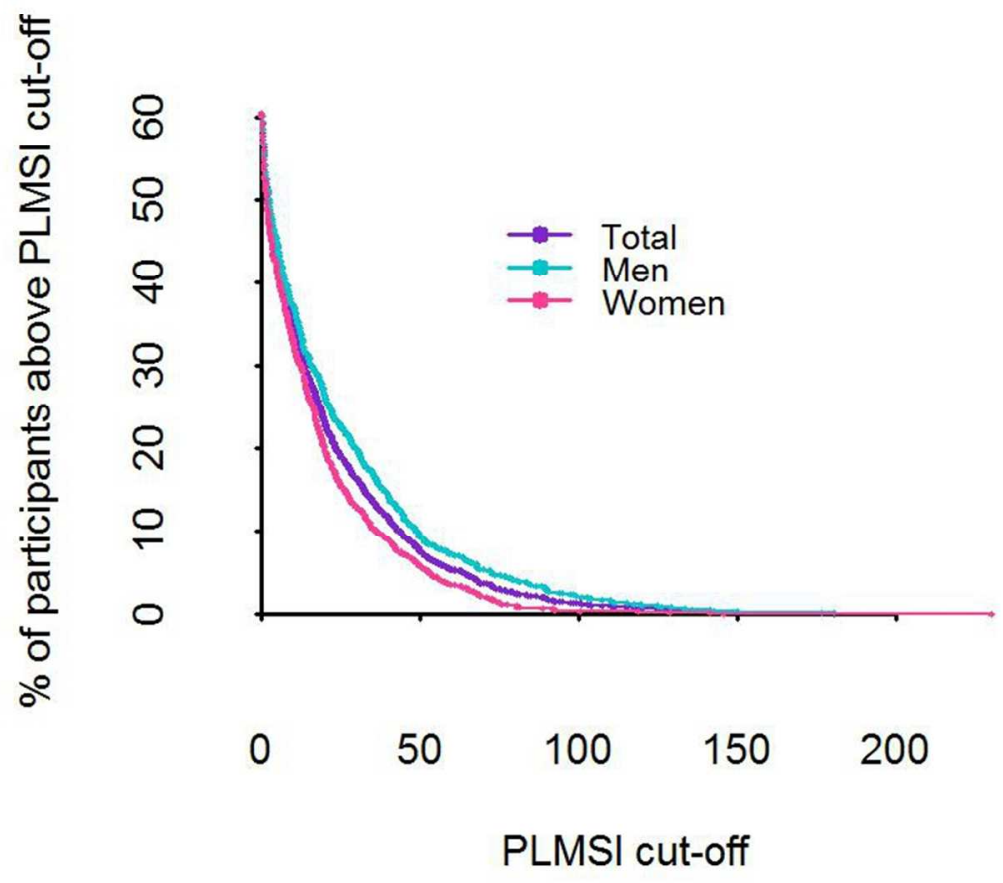

Figure 1: Studied population $79 \times 79 \mathrm{~mm}(300 \times 300$ DPI $)$

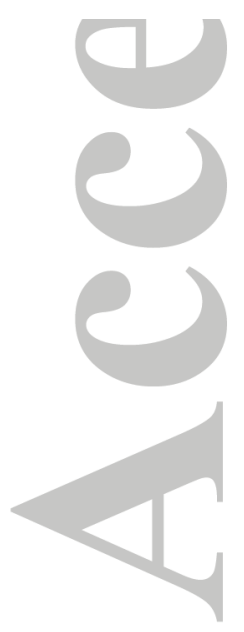

\section{John Wiley \& Sons}

This article is protected by copyright. All rights reserved. 